Guardia Calvo, Isadora.

Profesora Titular Escola Universitària ERAM-UdG. Grup de Recerca: ERAMSCI.

\title{
Mamá estuvo aquí: imagen, cuerpo y memoria en el arte visual contemporáneo.
}

\author{
TIPO DE TRABAJO
}

Comunicación.

PALABRAS CLAVE

Fotografía, mapping, collage, memoria, desaparición.

KEY WORDS

Photography, mapping, collage, memory, disappearance.

\section{RESUMEN}

Los acontecimientos históricos producidos en América Latina, principalmente entre las décadas de los 70 y 80 en Argentina y Chile, suponen una situación de limbo emocional para miles de personas que, en algunos casos, encuentran en la producción artística un modo de resiliencia. Además se crean políticas de restitución. La violencia y la desaparición hacen del trauma un estado permanente en una generación de hijos e hijas negados a ojos del poder hegemónico. La necesidad del cuerpo como un lugar cierto, físico, soporte y orilla en donde refugiarse irrumpe de una manera evidente en el trabajo de Verónica Maggi y Lucila Quieto. La hibridación entre lo análogico y lo virtual en el caso del mapeado de Verónica Maggi y Lucila Quieto va más allá del proceso numérico o fotoquímico de materialización de la imagen y se desplaza hacia el problema real surgido de los hechos materiales y su posterior nombramiento lingüístico: "Ni vivos ni muertos".

\section{ABSTRACT}

Historical events produced in Latin America, mainly between the decades of the 70's and 80's in Argentina and Chile, represent a situation of emotional limbo for thousands of people who, in some cases, find in artistic production a mode of resilience. Moreover, restitution policies are created. Violence and disappearance transform the trauma into a permanent state within a generation of sons and daughters, who are refused by hegemonic power. The art of Veronica Maggi and Lucila Quieto searches the necessity of the body as a strong physical support. The hybridization between what is analog and what is virtual -in the case of Veronica Maggi and Lucila Quieto's mapping- goes beyond the numeric process or photochemical materialization of the image and moves toward the real problem, which emerges from material facts and their subsequent appointment linguistic: "Neither alive nor dead".

\section{CONTENIDO}

Introducción

"En esta serie, parto de diapositivas proyectadas sobre mi cuerpo para intentar "recordar y rescatar a la madre que jamás conoci". Tal vez, más que una legitimación del pasado, sea una certificación del futuro: "Mirta, aunque muerta, tuvo un futuro, yo soy ese futuro".

(Verónica Maggi, 2007) $)^{1}$

\footnotetext{
${ }^{1}$ http://sombrasenllamas.blogspot.com.es/2013/03/veronica-maggi-fotografa-cordobesa.html Última visita 16/03/2015
} 

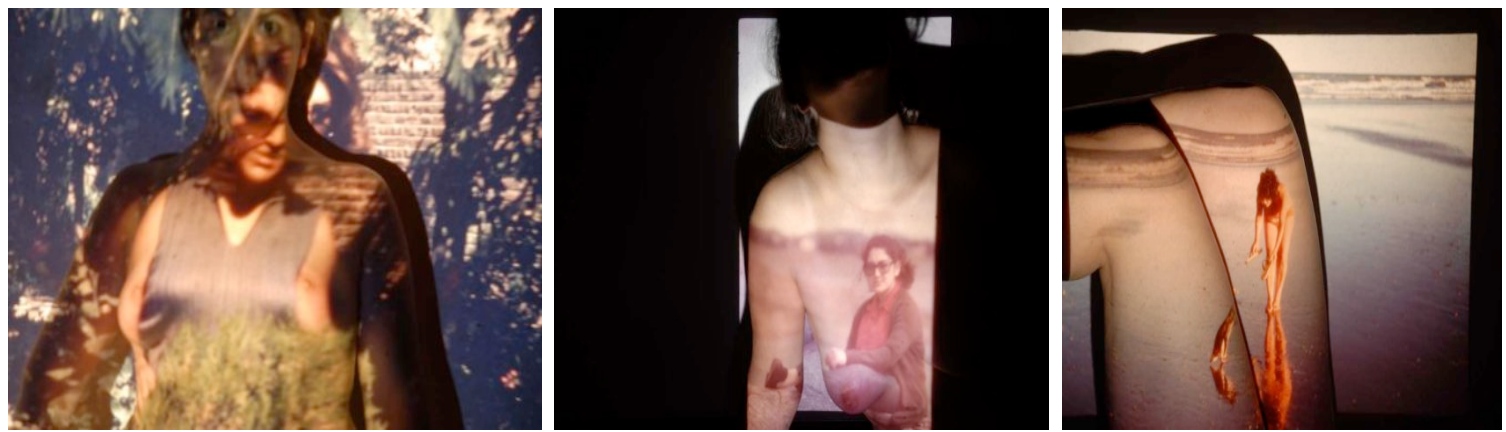

Figuras 1, 2, 3 Proyecto “El Rescate”, Verónica Maggi, 2007

La obra de Verónica Maggi, así como de otros artistas -en un gran número mujeres latinoamericanas- pone de manifiesto la urgencia de entretejer lo real y lo virtual con el objetivo de recuperar un espacio-tiempo arrebatado, no sólo como texto, sino como hecho. Los acontecimientos históricos producidos a lo largo y ancho de América Latina, principalmente entre las décadas de los 70 y 80 en Argentina y Chile, suponen una situación de limbo emocional y corpóreo para miles de personas que, en algunos casos, encuentran en la producción artística un modo de resiliencia además del modo de crear políticas de restitución. La violencia y la desaparición hacen del trauma un estado permanente en una generación de hijos e hijas negados a ojos del poder hegemónico.

Asegura Rocco Mangieri ${ }^{2}$ que "el cuerpo del desaparecido forzado y político se construye en un espacio de semiosis polémica [...]" por cuanto incluye una serie de estrategias discursivas basadas en la indiferencia y el eclipse (Mangieri, 2012). Limbo, olvido, desaparición, apropiación, surgen en aquello que Mangieri (2012) denomina semiótica militante. Algo así como un metadiscurso teórico que pueda dar cuenta "desde una mirada sociopolítica y ética, de la historia y del relato de la semiosis del poder [...]."

Frente a la organización de un discurso oficial que desarticula al sujeto y lo condena a esa suerte de limbo indefinible:

“¿Qué es un desaparecido? En cuanto éste como tal, es una incógnita el desaparecido. Si reapareciera tendría un tratamiento $X$, y si la desaparición se convirtiera en certeza de su fallecimiento tendría un tratamiento Z. Pero mientras sea desaparecido no puede tener ningún tratamiento especial, es una incógnita, es un desaparecido, no tiene entidad, no está, ni muerto ni vivo, está desaparecido."

(Jorge Rafael Videla, 1979 en Mangieri, 2012) ${ }^{3}$

Se producen una serie de intervenciones semióticas sobre los cuerpos que niegan precisamente la ausencia del referente por cuanto pretenden neutralizar la simulación. El significante muerto, afirma Mangieri, es ambiguo y equívoco desde una perspectiva jurídica. Diferente es el tratamiento desde la producción de sentido de los propios familiares como a continuación veremos.

Tal y como aseguraba en su crítica al postmodernismo Jörg Becker, la jerga sustituye el concepto por el fetiche, se produce una situación que más allá de la ficción se aproxima a la simulación, a la ausencia de realidad por cuanto desaparición del exterior (Méndez, 2004: 108). Del exterior y del cuerpo. Delante de una situación cercana al simulacro: "ni vivo ni muerto"; la silueta, el retrato, el álbum de fotos familiar remite a quien ha sido. La no condición de "ni muerto ni vivo" produce, además, la imposibilidad de generar la figura de "el que hizo desaparecer" dejando así un espacio de impunidad inasumible por los vivos.

\section{Desarrollo}

\section{Primeras manifestaciones. Siluetas y retratos}

Si Baudrillard (1991) inauguró la época de la virtualización del acontecimiento en la que la Guerra del Golfo no tenía lugar al ser simulacro y espectáculo televisivo, si los años 90 se convirtieron en la década por excelencia para negar la realidad o, al menos, sospechar de ella de manera constante (J. Sánchez-Navarro, A. Hispano, 2001); unos años antes se producían una serie de manifestaciones artísticas que acompañaron otro tipo de pronunciamiento físico y militante y que reclamaban el estatuto de lo real como única manera de recomponer la huella y acudir a lo material. ${ }^{4}$ En 1983 se produce la primera manifestación de carácter artístico colectivo y consciente en Buenos Aires. Ha quedado registrada en la bibliografía como El Siluetazo.

\footnotetext{
${ }^{2}$ https://grupovalec.wordpress.com/articulos/de-rocco-mangieri/de-la-memoria-y-del-olvido-el-cuerpo-del-desaparecido/

${ }^{3}$ Estracto de la conferencia de prensa de Videla en diciembre de 1979 recogido por Mangieri.

${ }^{4}$ Precisamente esta actividad corrobora lo propuesto por Méndez al abordar la postmodernidad como un tiempo que no es necesariamente global y que puede convivir con otros estados mentales, culturales, económicos y políticos en el mundo... Vid. Méndez 2004.
} 
Tres artistas, Aguerreberry, Flores y Kexel, proponen una obra que dé cuenta de la dimensión cuantitativa de la desaparición de seres humanos y del espacio que ocuparían aquellas treinta mil personas arrebatadas a sus familiares. La idea se basa en la propuesta de un artista polaco, Jerzy Skapski, que en 1978 reproduce de manera gráfica y cuantitativa la muerte diaria de 2.370 personas en Auschwitz (Longoni y Bruzzone comp., 2008: 27).

La idea de los artistas argentinos fue llevada a las Madres de la Plaza de Mayo que aprobaron el proyecto y matizaron una serie de aspectos que resultan del todo relevantes para la construcción de una semiosis del cuerpo del desaparecido y su representación visual.

Las siluetas recortadas a tamaño real quedaban ausentes de nombres propios puesto que no había un recuento oficial de todas las víctimas, se tenían que incorporar cuerpos de mujeres embarazadas y de niños y el requisito más importante era la negativa a pegarlas en el suelo de manera que quedaran tendidas en el espacio de manera horizontal.

La articulación de la significación es clara. La silueta marcada a tiza, con cinta adhesiva, etc., es propia de la identificación del lugar donde se ha cometido un crimen y delimita físicamente el cuerpo del fallecido. Las Madres de la Plaza de Mayo reclamaban a sus hijos vivos. "Vivos los llevaron, vivos los queremos". 5

Las siluetas debían quedar erguidas, enganchadas a las paredes, interpelando desde el vacío rebosante del papel en blanco la mirada proyectada sobre el horror del espectador. Cualquiera de aquellas siluetas podría ser un padre, un hermano, un amigo. Poco a poco las siluetas se fueron llenando de frases, nombre propios, corazones recortados en color rojo. La participación masiva de viandantes y manifestantes que se ofrecían como modelos, que cortaban y pegaban cuerpos de papel hizo innecesaria la presencia de los artistas.

"Yo pongo el cuerpo".

La representación del desaparecido invalida la negación del referente puesto que apela a alguien que ha estado, que todavía es. La negativa a la silueta en tierra supone la construcción semiótica militante de un espacio y el rechazo a la estrategia retórica que propone el limbo como único lugar recognoscible. El tiempo de la mirada en relación dialéctica; la de un cuerpo (el que mira) y la representación del otro (el que ya no está), apela al instante aurático benjaminiano aunque, paradójicamente, la producción de siluetas sea en serie. Sin embargo esta serialización no tiene que ver con la producción de la obra con valor de exhibición sino que alude y acusa a la producción en serie de la destrucción, aquella que mantiene la lógica capitalista no sólo en el ámbito económico y simbólico sino en el físico.
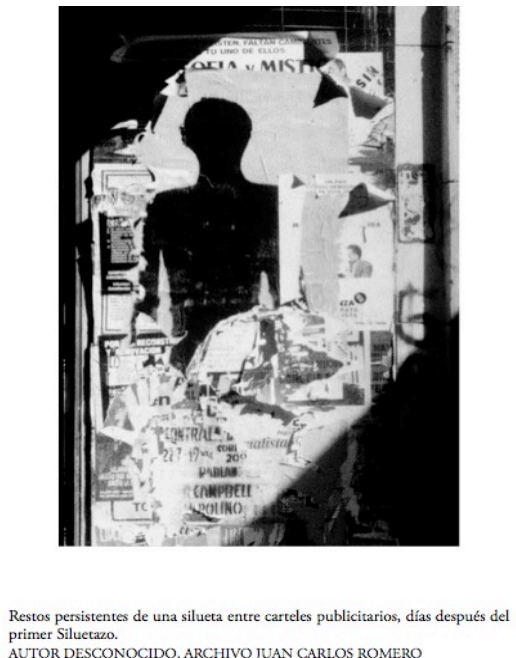

Figura 4. Imagen extraída de la publicación El Siluetazo, Adriana Hidalgo Editora, 2008

\subsection{El retrato. Estamos aquí}

Si El Siluetazo supone un punto de partida para las manifestaciones visuales colectivas, creativas y participativas en serie; el retrato se erige como la primera forma de manifestación reivindicativa desde lo visual. Las primeras fotografías se remontan a 1977 cuando las primeras Madres portaban con ellas las imágenes, los rostros, de los hijos desaparecidos.

\footnotetext{
${ }^{5}$ Esta voz ha recorrido principalmente Latinoamericana durante las décadas de los 70 y 80 y da título a un documental sobre los desaparecidos por la Guerrilla Blanca en México en los 70.
} 


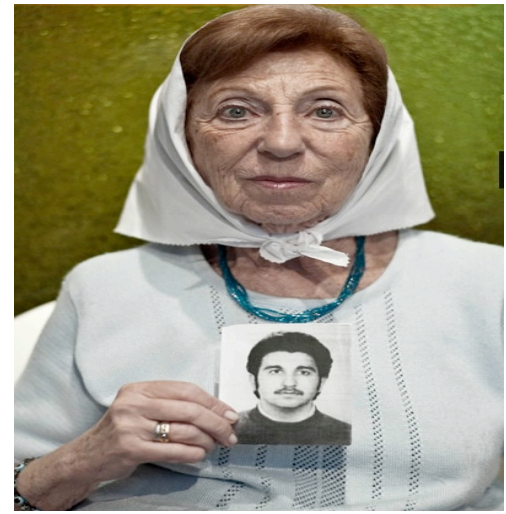

Fig. 5 Fotografía extraída de la exposición Desaparecidos. Víctimas del olvido. de Gervasio Sánchez.

Beatriz Lewin, madre de Jorge Marcelo Dyszel, desaparecido el 18 de mayo de 1978 en Buenos Aires (Argentina).

El rostro que mira a cámara, la fotografía en blanco y negro, lo particular e íntimo se apoya literalmente sobre el regazo materno y alude al proceso en sí de búsqueda. El carácter principalmente informativo de la fotografía se asemeja a cualquier trámite administrativo requerido. De igual manera entonces que el Estado exige la identificación-imagen del ciudadano, la utiliza para secuestrarlo y hacerlo desaparecer. Pero la imagen queda y la copia, por fin, adquiere el factor revolucionario al que Benjamin siempre aspiró (1989).

Siguiendo a Longoni y Bruzzone, las estrategias visuales son bien distintas y generan pares opuestos no excluyentes entre lo masivo y lo particular, lo anónimo y el nombre propio, el reclamo de justicia y el recuerdo íntimo (2008: 57). El exterior, como lugar cargado de sentido, equivale al contexto, en él, la fotografía, el retrato, es el texto. Todo aquello que es arrebatado en el ámbito privado y familiar, los desaparecidos, se presenta en el espacio público y es socializado. El cuerpo arrebatado a las madres, la inmediatez de los acontecimientos y la urgencia de la todavía posibilidad de encontrarlos con vida condiciona la expresión de la reivindicación. Se trata de factores materiales los que determinan la aparición con vida o la muerte y, por ende, su expresión artística. Las siluetas se reapropian de un espacio arrebatado y lo dotan de carácter artístico. La calle convertida en museo abierto. Sin embargo, el paso de los años y la confirmación del no retorno supone nuevas formas de enfrentarse y materializar la realidad. Es significativo la suma a este tipo de participación de los hijos e hijas de desaparecidos. La búsqueda es ahora, por tanto, la de la identidad.

\section{Collage y Mapping contra el Olvido. (No hay determinismo tecnológico que valga)}

Volviendo a Becker, su crítica a la asunción posmoderna de que nada puede parar los cambios tecnológicos iniciados desde la segunda bien entrada mitad del siglo XX y, sobre todo, el hecho de que estos cambios tecnológicos sirvan para perpetuar la expansión del capitalismo de consumo y una cultura y sociedad tecnocráticas y acríticas, sirve aquí para confirmar la excepción a la regla. Las nuevas propuestas visuales en torno a la recuperación del cuerpo y, por ende, la presencia real del desaparecido, utilizan las nuevas tecnologías para proponer un salto cualitativo en la representación efectuada hasta entonces. Juega lo simbólico y lo material.

\subsection{Verónica Maggi. El rescate}

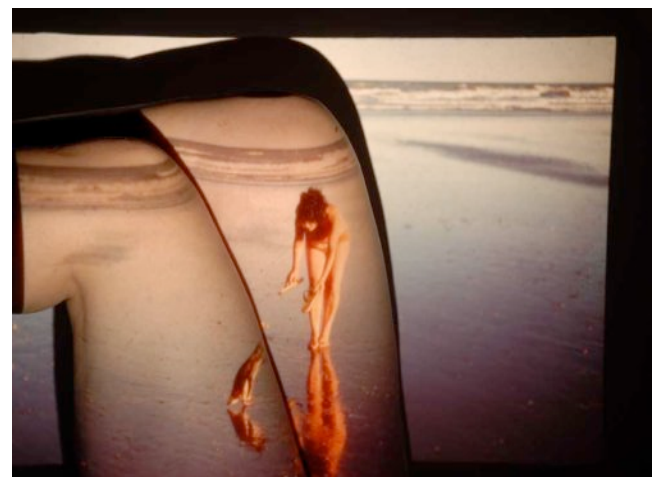

Fig. 6 Proyección mapeada “El Rescate" V. Maggi, 2007

La necesidad de lo corpóreo como un lugar cierto, físico, soporte y orilla en donde refugiarse irrumpe de una manera evidente en el trabajo de Verónica.

El recorrido desde las primeras fotografías informativas, los retratos que apelan al otro y evidencian la mirada mecánica del 
artefacto dieron paso a las siluetas, anónimas, masivas y políticas. El espacio sobre el que intervenir era aquel que permitía la apariencia del no ser y no saber escabuyéndose, así, de la verdad. Las siluetas interpelaban sin ojos ni boca, remitían al cuerpo y a la falta de su presencia. En las propuestas de los primeros años del nuevo siglo es posible atisbar la necesidad de identidad del que produce la obra. En efecto, la madre de Verónica impregna la piel de su hija, ella es gracias a una existencia previa. La artista es la demostración de la vida de su madre.

El juego de la proyección, la capacidad ilusoria de la luz permite corporeizar. Una pierna produce la extensión de la madre. La saca de la imagen y la torna material, la remite al presente. Mamá estuvo aquí. Mamá está aquí.

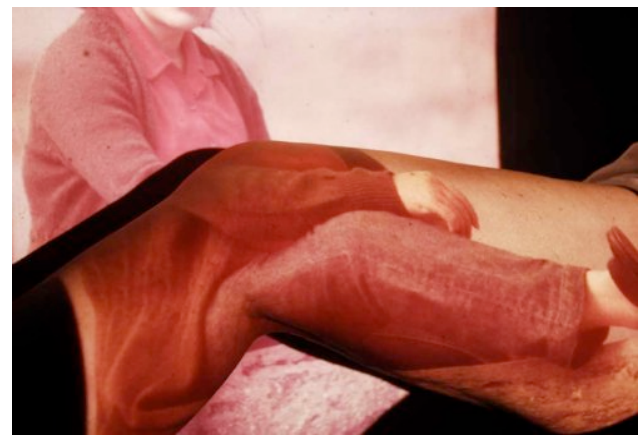

Fig. 7 Imagen proyecto “El Rescate" de Verónica Maggi

\subsection{Lucila Quieto. Arqueología de la ausencia}

Lucila Quieto, fotógrafa argentina nacida en 1977, inicia un proyecto titulado "Arqueología de la Ausencia" que permite reunir hijos y padres en un álbum de fotos familiar proyecto. Literal y simbólico. Literal por cuanto se emplea la misma técnica de mapeado que utiliza Verónica Maggi. Proyección de fotografías de los ausentes sobre una pared y la incorporación de los cuerpos de los hijos sobre ellas. Simbólico por cuanto reconstruye un pasado que nunca existió. Madre e hija se encuentran en un espacio-tiempo creado ex profeso. Un tercer tiempo, onírico, imaginado, en palabras de Longoni (2010: 276 en Larralde, 2013). La capacidad fantasmagórica que tiene la imagen por congelar el tiempo, por hacer perdurar lo imperdurable que tanto fascinaba a Bazin tiene una doble función dentro del álbum fotográfico familiar. Es capaz de crear una narrativa particular, sobre la que hilar la vida gracias a aquellos acontecimientos habitualmente felices, y también, adquiere un valor de documento histórico y colectivo. Advierte Korstanje (2014: 263) del peligro de colapso y fragmentación que puede sufrir una sociedad en la que no es posible recuperar física y simbólicamente los cuerpos. El desaparecido ha sido forzado a una situación que no ha elegido, supone la imposibilidad de ejercer el duelo de quien espera.
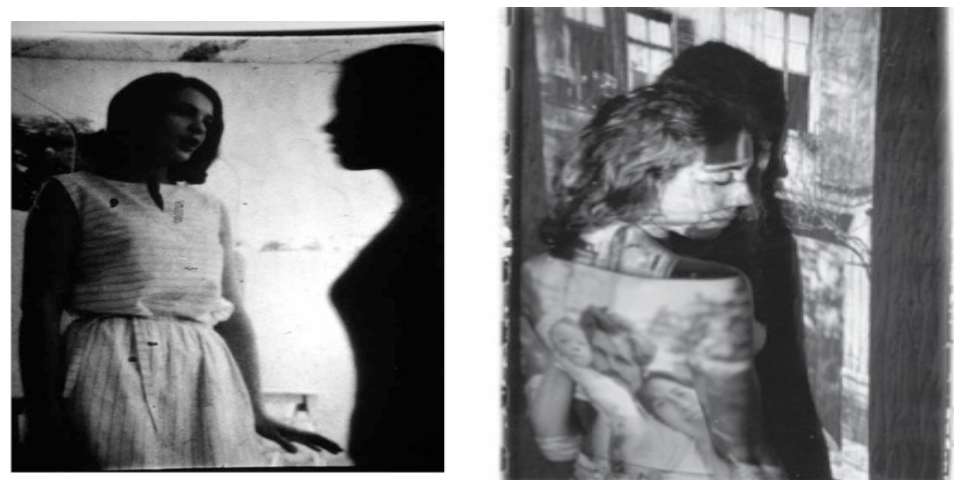

Fig. 8 y 9 Proyección “Arqueología de la ausencia” Lucila Quieto, 2013

Mientras las Madres de la Plaza de Mayo reclaman a sus hijos grabados en la memoria mediante fotografías identificativas, actuadas, los hijos y las hijas reclaman quiénes son ellos mismos superando un vacío material, emocional y visual. No existe álbum de fotos, no hay constancia de los momentos felices. No existieron. La espalda sirve de lienzo sobre el que se inscribe la propia existencia de la modelo-hija. Mientras las siluetas evidenciaban la presencia de la ausencia; los cuerpos de los hijos e hijas sirven para manifestar la ausencia presente. La representación, por tanto, adquiere lecturas de tipo platónico y aristotélico según la incógnica repose sobre la memoria o sobre la imaginación.

Pero la pregunta que subyace es si realmente es posible hablar de representación en el caso del álbum familiar mapeado. La virtualidad del acontecimiento busca de manera paradójica la afirmación de un referente y, por tanto, esta condición negaría en si misma la propia realidad virtual. Es hiperreal en términos baudrillardianos al ser simulada una realidad que no ha existido pero en la propia simulación queda expuesta la voluntad de volver al referente: el cuerpo. En la performatividad de la expresión, el cuerpo real sobre la proyección del haz de luz que construye la imagen fotográfica, se inscribe la necesidad de lo material. En la obra de Lucila 
también es posible encontrar la técnica del collage. Con el objetivo de construir un árbol genealógico especultaivo, la artista juega con los rostros de los familiares y el suyo propio. La pregunta que acompaña a este proceso es quizás si las muestras de lo físico, los rasgos, pueden corroborar el vínculo.

\section{Conclusiones}

El entretejido entre lo real y lo virtual comporta cierta disolución semiótica. Cuando el proceso constructivo de la imagen se desarrolla mediante la imagen digital se tiende a pensar que supone la supresión o eliminación de la huella. La fuerte creencia de la no-preexistencia o la nada fuera de los programas en los que la imagen se origina forma parte de la discusión abierta sobre la posibilidad de la representación desde lo virtual (Jullier, 2004: 75). Y como en ocasiones es posible comprobar, la problemática se encuentra en el signo lingüístico y no en el visual. De hecho, las expresiones visuales presentadas en este breve e incipiente estudio vienen a confrontar la condición afirmativa del lenguaje verbal cuando establece nuevas categorías dentro de la práctica social. La figura del desaparecido supone la instalación de un nuevo estado, el no-estado, y que llevaría a la lógica de su irrepresentabilidad.

Las primeras manifestaciones analógicas: fotografía química de retratos y la visualización gráfica de El Siluetazo contienen en sí mismas la huella tradicional, el indicio. Recodamos la insistencia de las Madres de la Plaza de Mayo por no representar los cuerpossilueta en posición horizontal y sobre el suelo. La hibridación entre lo análogico y lo virtual en el caso del mapeado de Verónica Maggi y Lucila Quieto va más allá del proceso numérico o fotoquímico de materialización de la imagen y se desplaza hacia el problema real surgido de los hechos materiales y su posterior nombramiento lingüístico: "Ni vivos ni muertos" (Videla). A su vez, la condición real de la no aparición con vida después de treinta o cuarenta años supera la genealogía planteada en los collage de Lucila y proyecta sobre los descendientes la constatación de la huella constante iniciada por las Madres de la Plaza de Mayo.

\section{FUENTES REFERENCIALES}

Baudrillard, J. (1991) La Guerrra del Golfo no ha tenido lugar, Barcelona: Anagrama

Benjamin, W. (1989) "La obra de arte en la era de su reproductibilidad técnica” en Discursos Interrumpidos I, Buenos Aires: Taurus

Jullier, L. (2004) La imagen digital. De la tecnología a la estética, Buenos Aires: La Marca

Korstanje, M. (2014) “Antropología de la memoria. De la represión al genocidio” en Revista de Antropología Experimental, Num. 14, Universidad de Jaén, España

Larralde, F. (2013) “Lucila Quieto, hijos atravensando el paisaje: Imágenes para construir el recuerdo añorado" en Revista Aletheia, Vol.4, Num.7, Octubre.

Longoni, A. Y Bruzzone, G. (comp.) (2008) El Siluetazo, Buenos Aires: Adriana Hidalgo editora

Mangieri, R. (2012) "De la memoria y del olvido. El cuerpo del desaparecido" en:

https://grupovalec.wordpress.com/articulos/de-rocco-mangieri/de-la-memoria-y-del-olvido-el-cuerpo-del-desaparecido/ Última visita $12 / 05 / 2015$

Méndez, A. (2012) La desaparición del exterior. Cultura, crisis y fascismo de baja intensidad, Zaragoza: Eclipsados

Sánchez-Navarro, J. e Hispano, a. (2001) Imágenes para la sospecha. Falsos documentales y otras piruetas de la no ficción, Barcelona: Glenat 